\title{
Electrochemical Impedance Study of Zinc Yellow Polypropylene-Coated Aluminum Alloy
}

\author{
Zhi-hua Sun, ${ }^{1}$ Jian-ping Cai, ${ }^{1}$ Ming Liu, ${ }^{1}$ Feng Lu, ${ }^{1}$ and Ni Zhang ${ }^{2}$ \\ ${ }^{1}$ Lab of Metal Corrosion and Protection, Beijing Institute of Aeronautics Materials, Beijing 100095, China \\ ${ }^{2}$ School of Material Science and Engineering, Beihang University, Beijing 100083, China
}

Correspondence should be addressed to Zhi-hua Sun, zhihuasun2002@yahoo.com.cn

Received 10 May 2009; Revised 7 October 2009; Accepted 3 November 2009

Academic Editor: Flavio Deflorian

Copyright ( $) 2010$ Zhi-hua Sun et al. This is an open access article distributed under the Creative Commons Attribution License, which permits unrestricted use, distribution, and reproduction in any medium, provided the original work is properly cited.

Performance of zinc yellow polypropylene-coated aluminum alloy 7B04 during accelerated degradation test is studied using electrochemical impedance spectroscopy (EIS). It has been found that the zinc yellow polypropylene paint has few flaw and acts as a pure capacitance before accelerated test. After 336-hour exposure to the test, the impedance spectroscopy shows two time constants, and water has reached to the aluminum alloy/paint interface and forms corrosive microcell. For the scratched samples, the reaction of metal corrosion and the hydrolysis of zinc yellow ion can occur simultaneously. The impedance spectroscopy indicates inductance after 1008-hour exposure to the test, but the inductance disappears after 1344-hour exposure and the passivation film has pitting corrosion.

\section{Introduction}

Organic coatings have been widely applied to control the corrosion of airplanes for many years $[1,2]$. The performance of organic coatings, which generally relates to their barrier performance character against water, oxygen, and ions and to their good adhesion to substrate impeding delamination, seriously influences their protection efficiencies to metallic substrates [3, 4]. However, organic coatings can degrade under various service conditions and the degradation process of paints is complicated since it is affected by several factors, such as humidity, heat impact, ultraviolet (UV) radiation, salt fog, pollutants (like $\mathrm{SO}_{2}$ ), low temperature fatigue, and other exotic (like dust) $[5,6]$. The degradation evaluation can be visual, mechanical, electrochemical, and so furth. The use of electrochemical techniques combined with accelerated tests has resulted in new information concerning the degradation mechanisms of organic coatings in corrosive environments $[7,8]$. In particular, electrochemical impedance spectroscopy (EIS) has been shown to be very useful technique for the study of the performance of anticorrosive primers $[9,10]$.

Zinc yellow polypropylene primer has been widely used in aeronautical industry, and its EIS study has been carried out. But the research mainly focus on its impedance measurement with exposure time after immersion to certain solution, such as $\mathrm{NaCl}$ solution $[11,12]$, and the failure characteristics after exposure to accelerated test simulating the service conditions have not been investigated.

In the present work, electrochemical impedance varieties of zinc yellow polypropylene-coated aluminum alloy 7B04 used in aircraft during accelerated test to simulate its service condition are studied using EIS, and the characteristics of corrosive failure of the organic coating are also investigated. This will provide useful information for predicting its service life.

\section{Experimental}

2.1. Sample Preparation. Chemical composition of the test 7B04 aluminum alloy is listed in Table 1. 7B04 aluminum alloys are cut into $100 \mathrm{~mm} \times 50 \mathrm{~mm} \times 2 \mathrm{~mm}$ shaped sheets, polished and then cleaned by ethanol. Then the samples are electrochemically anodized according to HB/Z 233-93 [13] before being painted. The zinc yellow polypropylene primers are applied in 24 hours after being anodized to ensure the good adhesion between the organic coating and the substrate. The thickness is approximately $40 \mu \mathrm{m}$. 
TABLE 1: Chemical composition of 7B04 Aluminum alloy (wt.\%).

\begin{tabular}{lcccccccc}
\hline Material & $\mathrm{Al}$ & $\mathrm{Zn}$ & $\mathrm{Mg}$ & $\mathrm{Cu}$ & $\mathrm{Mn}$ & $\mathrm{Cr}$ & $\mathrm{Fe}$ & $\mathrm{Si}$ \\
\hline 7B04 & bal & $5.0 \sim 6.5$ & $1.8 \sim 2.8$ & $1.4 \sim 2.0$ & $0.2 \sim 0.6$ & $0.1 \sim 0.25$ & $0.05 \sim 0.25$ & 0.1 \\
\hline
\end{tabular}

TABLE 2: Method of accelerated degradation test.

\begin{tabular}{lccc}
\hline No. & Process & Test Parameters & Duration \\
\hline 1 & UV Radiation & 8h UV Radiation at $60^{\circ} \mathrm{C}+4 \mathrm{~h}$ Humidity at $50^{\circ} \mathrm{C}(\mathrm{RH} 100 \%)$ & One Week \\
& & $2 \mathrm{~h} \mathrm{Salt} \mathrm{Fog}(3.5 \% \mathrm{NaCl}) / 35^{\circ} \mathrm{C}$ & One Week \\
2 & Cycling Salt Fog & $0.5 \mathrm{~h} \mathrm{Dry} / 40^{\circ} \mathrm{C}$ & \\
& & $1.5 \mathrm{~h} \mathrm{Dry} / 60^{\circ} \mathrm{C}$ & \\
3 & Go to Process 1 & & \\
\hline
\end{tabular}

The artificial defect was obtained by scratching the coating with a hand cutter reaching to the metallic substrate. The representative appearance of the specimen with scratches is shown in Figure 1.

2.2. Accelerated Degradation Test. It is well known that the degradation of the organic coatings is not only determined by UV radiation, temperature, and humidity but also by pollutants. The damaging effects of sunlight are simulated by fluorescent UVA-340 lamps. The method of accelerated degradation test selected is listed in Table 2. The salt fog test and UV radiation are carried out in CCT Q-FOG chamber and QUV/SPRAY chamber of Q-Panel company, respectively.

2.3. EIS Measurement. The electrochemical properties of the paint are determined using EIS. A classical three-electrode cell is used for the electrochemical measurement: the working electrode with an exposed area of $10 \mathrm{~cm}^{2}$, the saturated calomel reference (SCE), and a platinum auxiliary electrode. The test solution is $0.5 \mathrm{M} \mathrm{NaCl}$. The impedance spectra are obtained at the rest potential (versus SCE) using an EG\&G 1025 frequency response detector coupled with an EG\&G 283 potentiostat. Both devices are computer controlled using Powersuite Software. The impedance measurements are carried out in a frequency range of $100 \mathrm{kHz}$ to $10 \mathrm{mHz}$. A sinusoidal ac perturbation of $20 \mathrm{mV}$ (versus SCE) coupled with the open circuit potential is applied to the intact paints and $5 \mathrm{mV}$ (versus SCE) for scratched samples. All the measurements are conducted at the room temperature $\left(\sim 25^{\circ} \mathrm{C}\right)$. The impedance data are fitted with electrical equivalent circuit models using ZsimpWin Software.

\section{Results and Discussion}

3.1. EIS Measurement Results of Samples without Scratches. Figure 2 shows the EIS Bode graph of coated samples before accelerated degradation test. It is showen that the phase angles are almost 90 degrees in a wide frequency range, and the impedances are as high as $10^{9} \Omega \cdot \mathrm{cm}^{2}$. The primers present a high ohmic resistance and thus can be treated

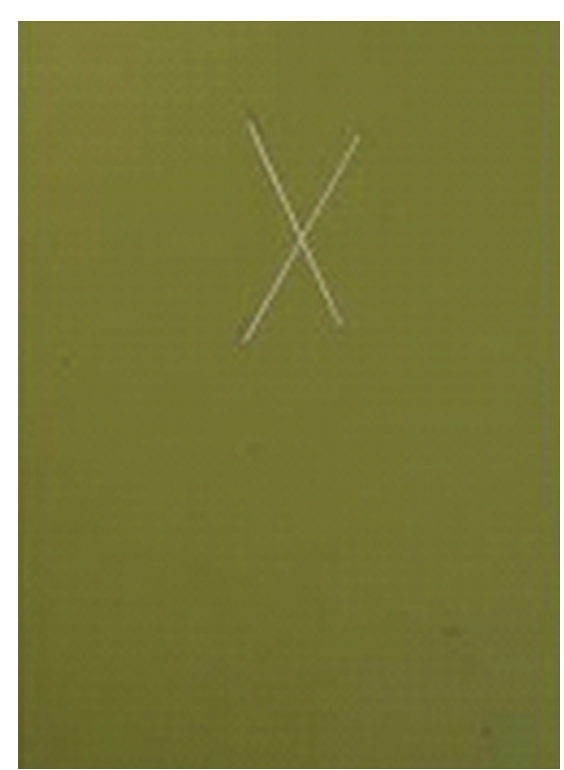

FIGURE 1: Scratched sample.

as a pure electric capacitor. This indicates that there are few flaws in the primers, and the primers are good barriers and can protect the metallic substrates from corroding. The equivalent circuit before accelerated degradation test of coated samples are showen in Figure 3. In this model, $R_{s}$ is the solution resistance; $C_{c}$ and $R_{p}$ are the paint capacitance and the coating resistance, respectively. According to the equivalent circuit, the coating capacitance before accelerated test calculated is very low and about $4.57 \times 10^{-9} \mathrm{~F} / \mathrm{cm}^{2}$.

As the exposure time increases, the EIS impedance spectra changes greatly. Figure 4 shows the EIS Bode graph, equivalent circuit and imitation result of coated samples after 336-hour exposure to accelerated degradation test. It displays two time constant characteristic and indicates that water has reached to the aluminum alloy/paint interface, and the corrosive microcell forms. Also in the low-frequency area, Warburg impedance behavior appears. 


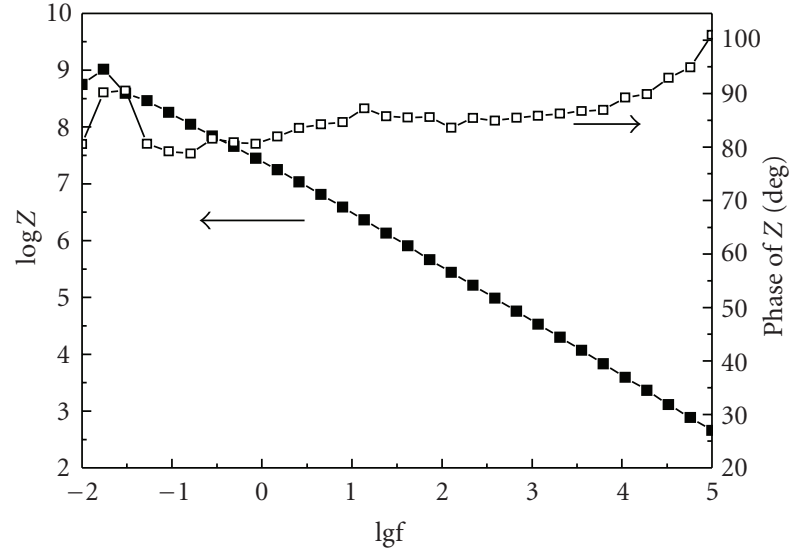

FIgURE 2: EIS Bode graph before accelerated degradation test of coated samples.

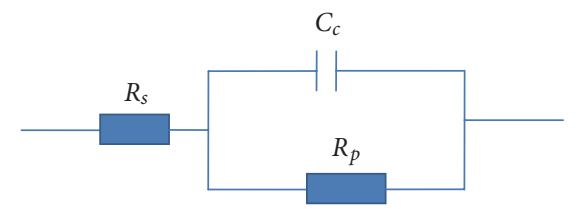

FIGURE 3: Equivalent circuit before accelerated degradation test of coated samples.

According to Zhang [14], the Warburg impedance usually appears at the later stage of immersion test. Also it is known that the anticorrosive pigment zinc yellow ion in the primers can hydrolyze and the reaction products, such as $\mathrm{K}_{2} \mathrm{CrO}_{4}$, and $\mathrm{ZnCrO}_{4}, \mathrm{Zn}(\mathrm{OH})_{2}$, and $\mathrm{Zn}_{2}(\mathrm{OH})_{4} \mathrm{CrO}_{4}$ can attach to the corrosive active area and inhibit the corroding. So the Warburg impedance in Figure 4 may be due to the hydrolysis products, and equivalent circuit is shown in Figure 4 . In the model of Figure $4, R_{s}$ is the solution resistance, $C_{c}$ and $R_{p}$ are the paint capacitance and resistance, respectively, $W$ is the diffusion impedance of the hydrolysis products of zinc yellow pigment, while $\mathrm{C}_{l}$ and $\mathrm{R}_{l}$ are the capacitance and resistance of the hydrolysis reaction. According to the equivalent circuit, the paint capacitance calculated is about $4.897 \times 10^{-9} \mathrm{~F} / \mathrm{cm}^{2}$, the resistance is about $4213 \Omega$ and the diffusion impedance is about $2.033 \mathrm{E}-5 \Omega$.

After 1680-hour exposure to accelerated degradation test, EIS Nyquist graph, equivalent circuit, and imitation result of coated samples are shown in Figure 5. It can be seen that the paint impedance decreases. In the stage, the anticorrosion effect due to the hydrolysis reaction of zinc yellow pigment gradually decreases, and the diffusion impedance of the hydrolysis products disappears. Furthermore, considering that water and oxygen molecules reach to the substrate surface, the electrochemical reactions at the metal/paint interface may take place and the pitting will occur. So the equivalent circuit shown in Figure 5 is introduced to fit the experimental data, in which $R_{s}$ is the solution resistance, $C_{c}$ and $R_{p}$ are the primer capacitance and resistance respectively, and $C_{l}$ and $R_{l}$ are the capacitance and resistance of the

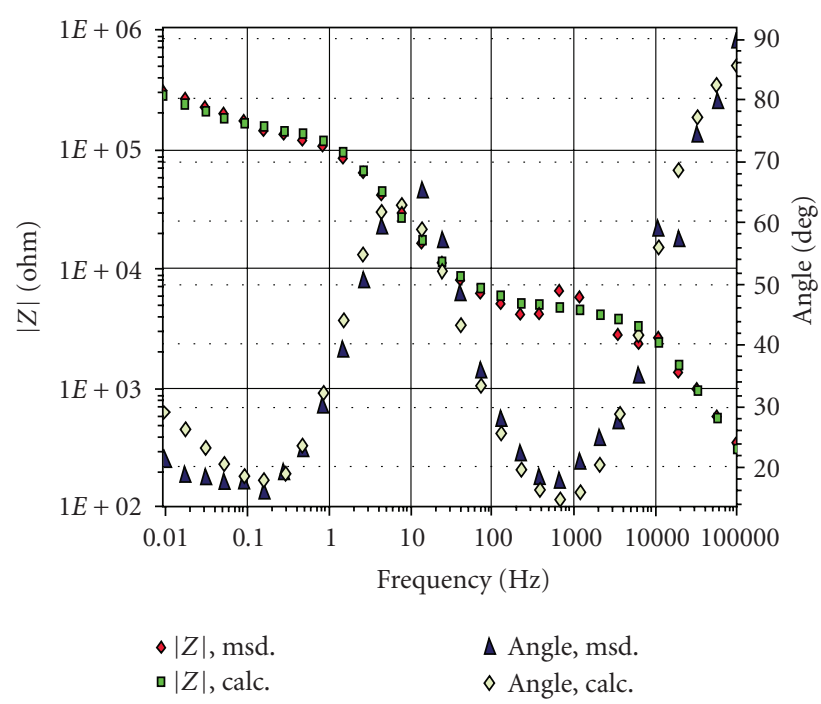

(a)

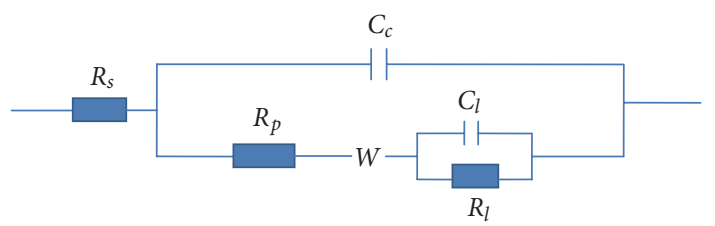

(b)

FIgURE 4: EIS Bode graph, equivalent circuit, and imitation result after 336-hour test.

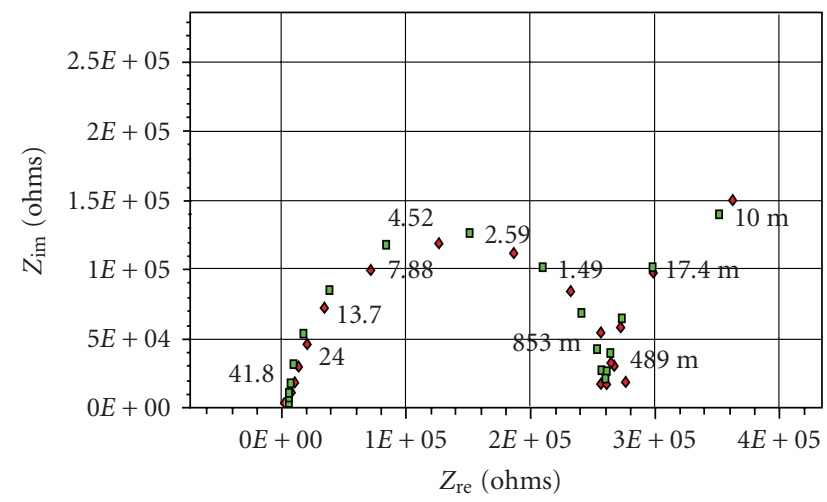

$\checkmark$ Z, Msd.

- $Z$, calc.

(a)

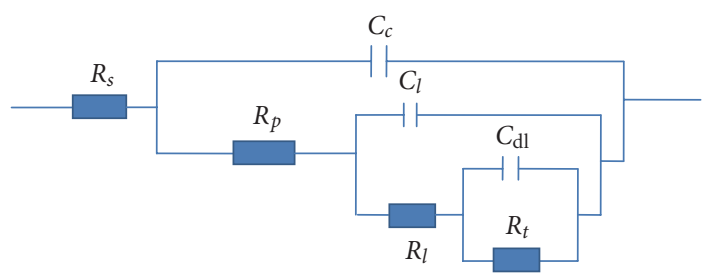

(b)

FIGURE 5: EIS Nyquist graph, equivalent circuit, and imitation result after 1680-hour test. 

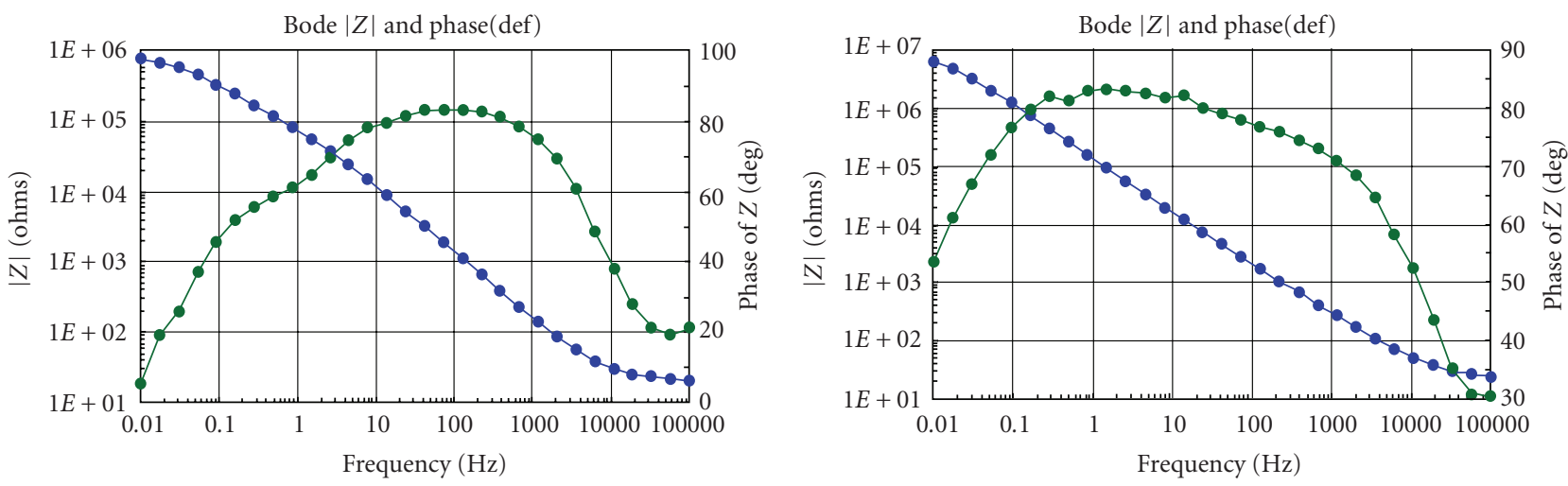

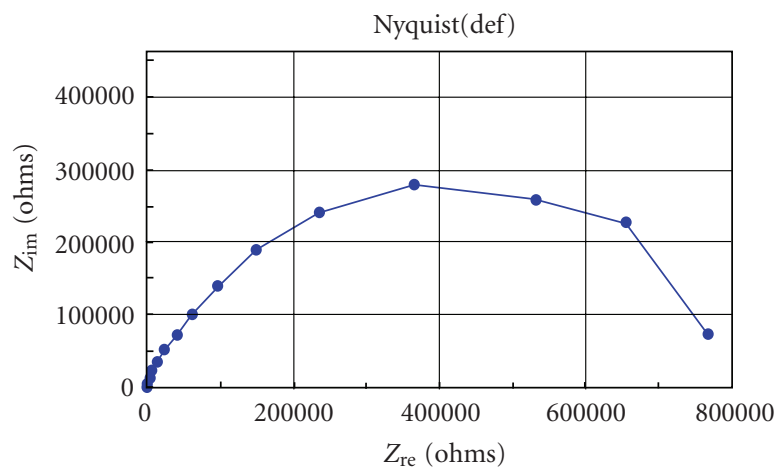

(a) Before exposure

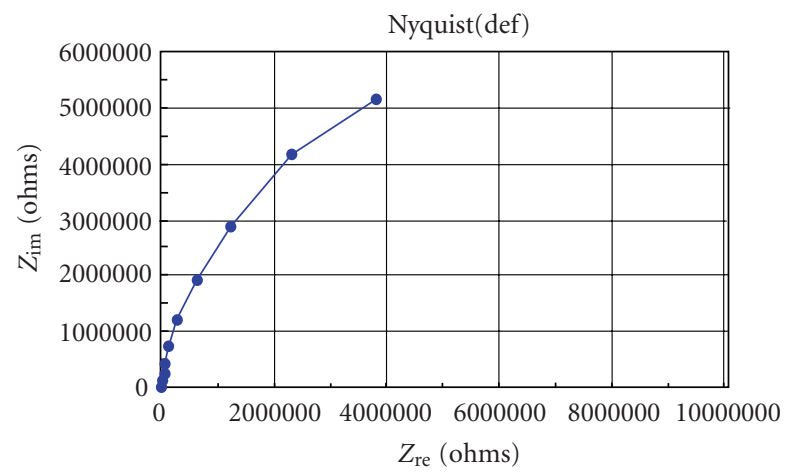

(b) After 336-hour exposure

FIGURE 6: EIS Bode and Nyquist graphs before and after 336-hour exposure to accelerated degradation test of coated samples.

hydrolyzing reaction, while $C_{d l}$ and $R_{t}$ are the double-layer capacitance and the reaction resistance on the metal/paint interface, respectively.

3.2. EIS Measurement Results of Samples with Scratch. The corrosion reaction of metal and the hydrolysis reaction of zinc yellow pigment are regarded to take place simultaneously on the scratches when there are scratches on the samples. Figure 6 shows EIS Bode and Nyquist graphs of coated samples with scratches before test and after 336hour exposure to accelerated test. It can be seen that the Nyquist graphs are all semicirculars for the two situations, and the radius of the semicircular after 336-hour test is larger than that before test. The reason is that the hydrolysis product of zinc yellow pigment can make the active areas along the scratch passivate. The morphologies of scratched samples after 336-hour and 1344-hour exposure are shown in Figure 7. It is shown that there is no corrosion along the scratch after 336-hour exposure shown in Figure 7(a).

Along with the exposure time, the EIS changes greatly. Figure 8 shows the EIS of scratched coated samples after 1008-hour and 1344-hour exposure to the test. It reveals that the inductance behavior appears and there is positive value in the low frequencies after 1008-hour exposure test. According to the above analysis, the hydrolysis products of zinc yellow pigment can passivate the active area along the scratch, and the passivation film is just in the pitting corrosion inducing stage. But after 1344-hour exposure test, the inductance behavior disappears, and it indicates that the passivation film has pitting corrosion. And there are corrosion products and pittings (shown in Figure 7(b)) along the scratches after 1344-hour exposure test.

From the results, it can be seen that the intact primer can quickly degrade under the accelerated test conditions though there are few flaws in the zinc yellow polypropylene primer before test. The reason is that the resistance to UV effect of the primer is not very good; so the water can quickly permeate into the primers because of the degradation.

In practice, there are some defects in the organic coatings, and the specimens with scratches can simulate the situation of the coatings with defects. Comparing the result of scratched samples with that of unscratched samples, it indicates that the reaction of metal corrosion and the hydrolysis reaction of zinc yellow ion can occur simultaneously for the samples with scratches, while for samples without scratches, the electrolyte should firstly permeate to the metal/paint interface through the micropores after certain aging time, and then the reaction of the substrate may occur.

\section{Conclusions}

Electrochemical techniques combined with accelerated tests which simulate its service conditions are applied to investigate the failure of zinc yellow polypropylene coating on 7B04 aluminum alloy. Intact and scratched samples were studied. 


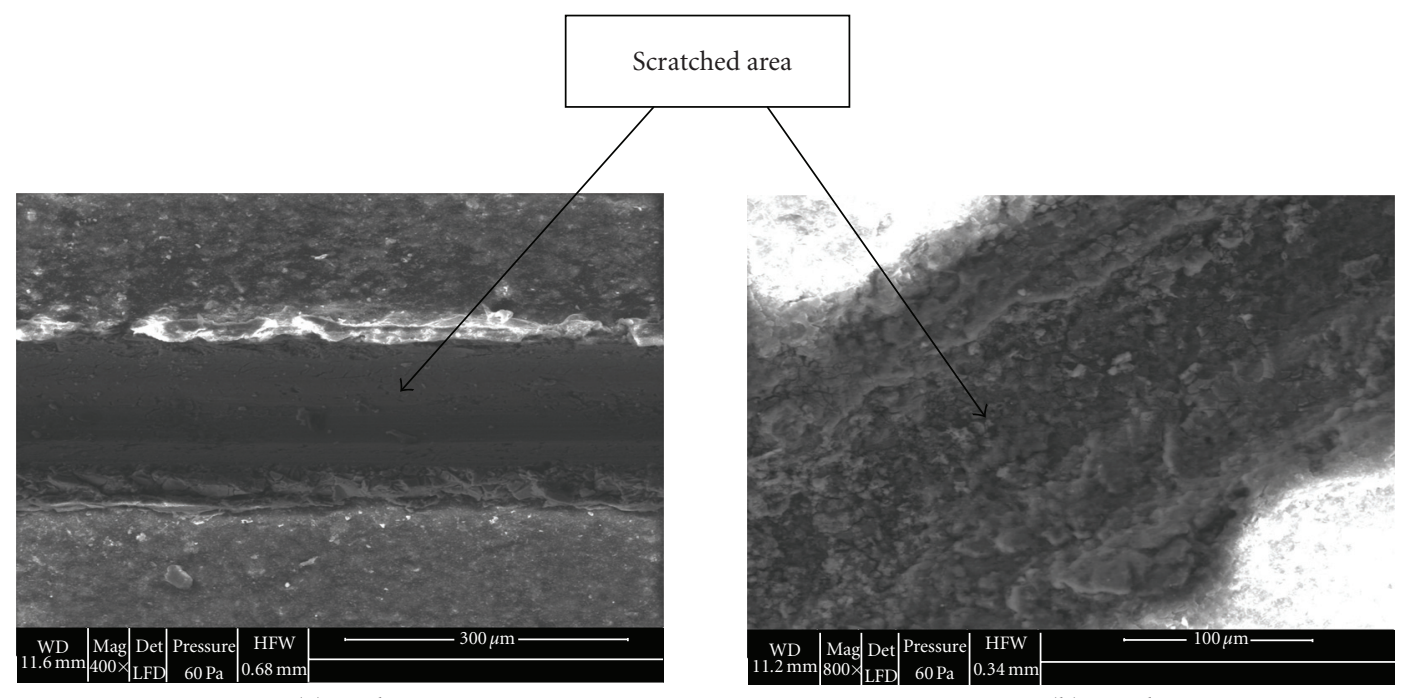

(a) $336 \mathrm{~h}$

(b) $1344 \mathrm{~h}$

Figure 7: Morphology of scratched samples after 336-hour and 1344-hour exposure test.

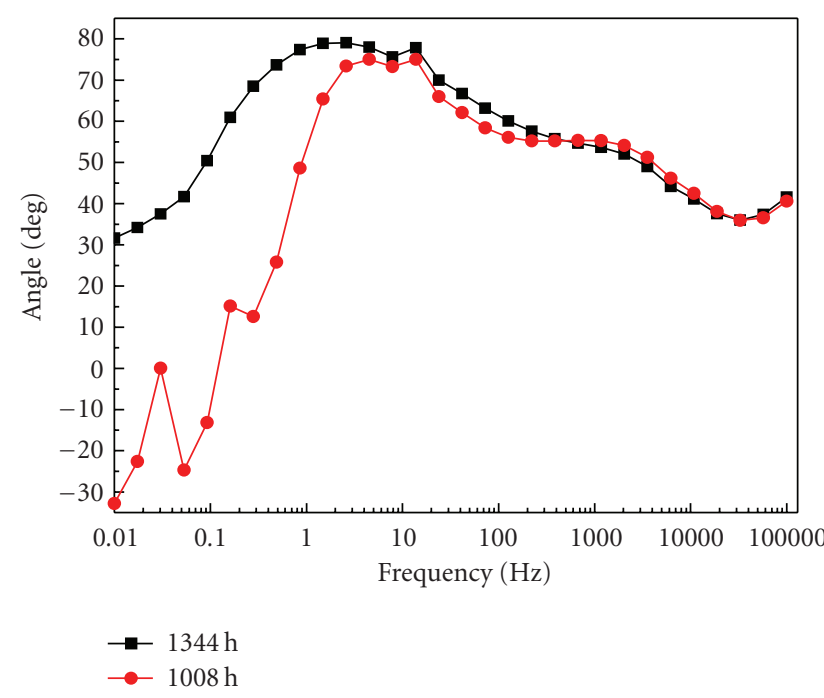

FIGURE 8: EIS of scratched coated samples after 1008-hour and 1344-hour exposure test.

Before test, the intact zinc yellow polypropylene coating acts as a pure capacitance before test, and the phase angles are almost 90 degree in a wide frequency range, and the impedances are as high as $10^{9} \Omega \cdot \mathrm{cm}^{2}$. But water can quickly permeate into the coating after exposure to the test, and the hydrolysis products of anticorrosive pigment zinc yellow ion can make aluminum alloy passivate. After 336-hour exposure to the test, the impedance spectroscopy shows two time constants.

For the scratched samples, the reaction of metal corrosion and the hydrolysis reaction of zinc yellow ion can occur simultaneously and the impedance spectroscopy indicates inductance after 1008-hour exposure. The hydrolysis products of zinc yellow pigment can passivate the active area along the scratch, and the passivation film is just in the pitting corrosion inducing stage. But after 1344-hour exposure test, the inductance behavior disappears, and it indicates that the passivation film has pitting corrosion. And there are corrosion products and pits along the scratches after 1344hour exposure test.

\section{Acknowledgments}

This work is supported by the National Defense Technology Foundation Project (H052006A006) and Weapon Equipment Pre-research Foundation Project (51412060305HK5104). The testing samples were kindly supplied by $\mathrm{Yu}$ XIONG from Lab of Organic Coatings in Beijing Institute of Aeronautical Materials.

\section{References}

[1] Q. Chen, Z. Sun, W. Lu, E. Han, T. Chang, and J. Li, "Comprehensive evaluation for anticorrosive properties of heavyduty coating SEBF/SLF applied to typical aircraft structures," Journal of the Chinese Society of Corrosion and Protection, vol. 25, no. 6, pp. 365-368, 2005.

[2] W. Liu, Y. Li, Q. Chen, and X. He, "Accelerated corrosion environmental spectrum for testing surface coatings of critical area of flight aircraft structures," Journal of Beijing University of Aeronautics and Aestronautics, vol. 28, no. 2, pp. 109-112, 2002.

[3] Y. Xu, C. Yan, J. Jing, Y. Gao, and C. Cao, "UV Photodegradation on coatins," Journal of Chinese Society for Corrosion and Protection, no. 6, pp. 168-173, 2004.

[4] Q. Chen, W. Liu, Z. Chen, and X. Qi, "Current status and key techniques of aircraft structure under corrosive environment," China Safety Science Journal, vol. 10, no. 3, pp. 42-47, 2000.

[5] C. P. Woodcock, D. J. Mills, and H. T. Singh, "Use of electrochemical noise method to investigate the anti-corrosive properties of a set of compliant coatings," Progress in Organic Coatings, vol. 52, no. 4, pp. 257-262, 2005. 
[6] X. Zhang, J. Gong, S. Tu, and F. Kong, "Study on the effect of coatings defects on the coating failure and corrosion behavior of substrate," Journal of Materials Science \& Engineering, vol. 21, no. 6, pp. 922-926, 2003.

[7] M. Poelman, M.-G. Olivier, N. Gayarre, and J.-P. Petitjean, "Electrochemical study of different ageing tests for the evaluation of a cataphoretic epoxy primer on aluminium," Progress in Organic Coatings, vol. 54, no. 1, pp. 55-62, 2005.

[8] J. H. Osborne, K. Y. Blohowiak, S. R. Taylor, et al., “Testing and evaluation of nonchromated coating systems for aerospace applications," Progress in Organic Coatings, vol. 41, no. 4, pp. 217-225, 2001.

[9] L. Wu, X. Hu, and C. Xu, "Methods for evaluating the performance of protective coatings with EIS," Corrosion Science and Protection Technology, vol. 12, no. 3, pp. 182-184, 2000.

[10] Z. Luo, P. Yao, J. Cai, X. Zhang, and F. Lu, "Progress of evaluation techniques for organic coatings performance," Corrosion Science and Protection Technology, vol. 16, no. 5, pp. 313-317, 2004.

[11] J. Hu, J. Liu, and D. Zhang, "EIS study of Zinc yellow epoxy ester primer for aluminum alloy," Materials Protection, vol. 35, no. 3, pp. 25-26, 2002.

[12] Y. Hu, D. Li, and B. Guo, "Study on evaluation for under-film corrosion of coated 2024 T3 aluminum alloy with EIS by time domain method," Journal of Chinese Society for Corrosion and Protection, vol. 22, no. 1, pp. 8-13, 2002.

[13] HB/Z 233-93 Sulphuric acid anodizing of aluminum and its Alloy.

[14] J. Zhag and C. Cao, "Study and evaluation on organic coatings by electrochemical impedance spectroscopy," Corrosion \& Protection, vol. 19, no. 3, pp. 99-104, 1998. 

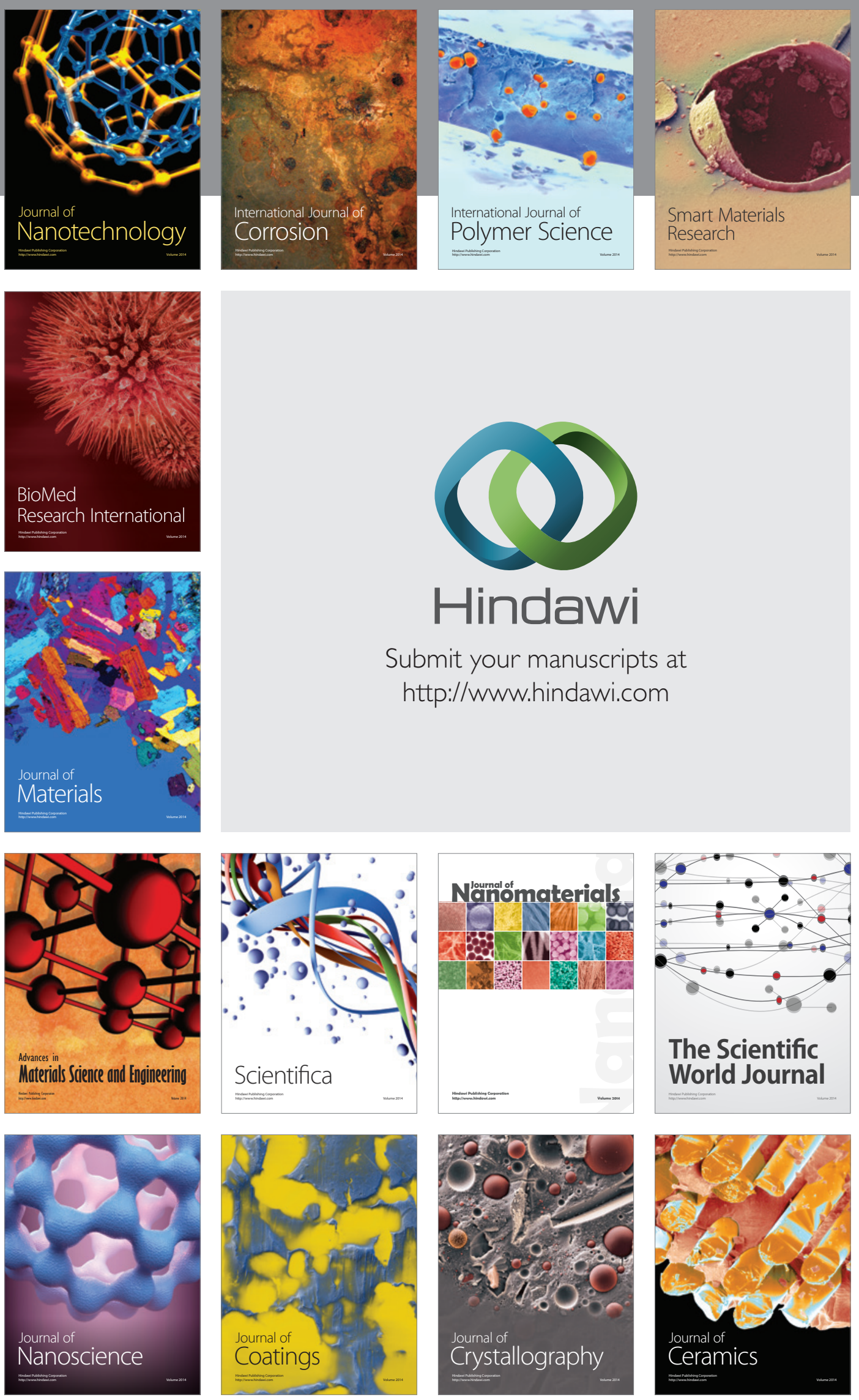

The Scientific World Journal

Submit your manuscripts at

http://www.hindawi.com

\section{World Journal}

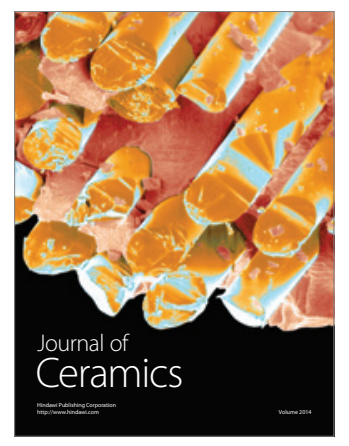

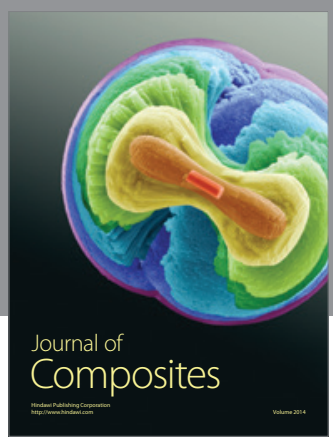
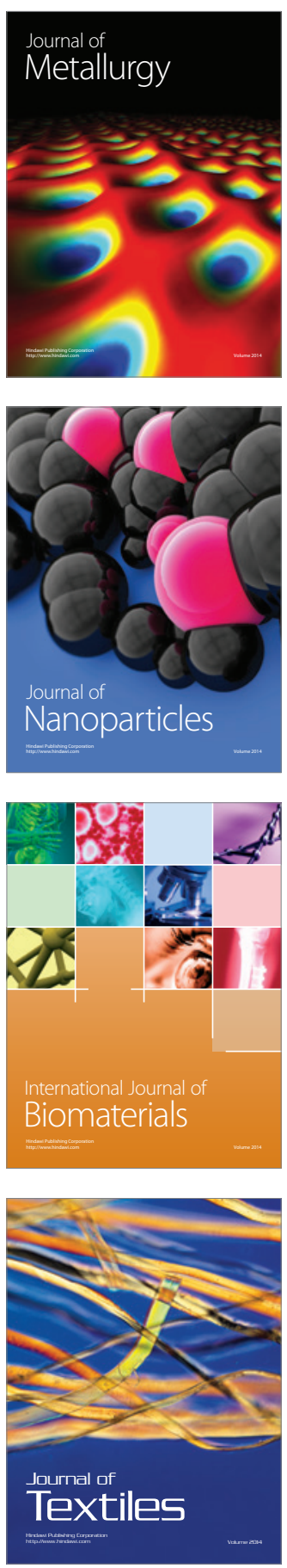